Authors' post print version of:

Smith CD, Masouros SD, Hill AM, Wallace AL, Amis AA, Bull AMJ. The compressive behaviour of the human glenoid labrum may explain the common patterns of slap lesions. Arthroscopy. 25, (2009),

504-509.

The original publication is available at http://www.sciencedirect.com/science/journal/07498063

\title{
THE COMPRESSIVE BEHAVIOUR OF THE HUMAN GLENOID LABRUM MAY EXPLAIN THE COMMON PATTERNS OF SLAP LESIONS
}

\section{RUNNING TITLE: GLENOID LABRUM COMPRESSIVE BEHAVIOUR}

CD Smith MB BCh MRCS ${ }^{1,2}$, SD Masouros Dipl Eng ${ }^{1,2}$, AM Hill MB PhD $^{1,3}$, AL Wallace FRACS ${ }^{4,5}$, AA Amis DSc (Eng) ${ }^{2,5}$, AMJ Bull PhD ${ }^{1}$

${ }^{1}$ Department of Bioengineering, Imperial College London, UK

2 Department of Mechanical Engineering, Imperial College London, UK

${ }^{3}$ Department of Biosurgery \& Surgical Technology, Imperial College London, UK

${ }^{4}$ The Shoulder Unit, Hospital of St. John \& St. Elizabeth, London, U.K.

${ }^{5}$ Department of Musculoskeletal Surgery, Imperial College London, UK

No external funding was obtained for this research and none of the authors benefited financially from it. All the primary data is available for review if requested and is completely under the control of the authors.

Each author certifies that his or her institution has approved the protocol for this investigation and that all investigations were conducted in conformity with ethical principles of research.

Corresponding author:

\author{
AMJ Bull PhD CEng FIMechE \\ Department of Bioengineering \\ Imperial College London \\ Room 4.31 Royal School of Mines \\ South Kensington Campus \\ London SW7 2AZ \\ Tel: +44 2075945186 \\ Fax: +44 2075846897 \\ Email: a.bull@imperial.ac.uk
}




\begin{abstract}
Purpose. The aim of the study was to define the normalised compressive stiffness (modulus) of the glenoid labrum around its circumference and to characterise the difference in modulus between different areas.
\end{abstract}

Methods. 16 fresh frozen cadaveric shoulders were harvested and dissected down to the glenoid labrum. Any specimens with significant degenerative changes were discarded, leaving eight labrae for testing. The labrum was divided into eight segments, to allow comparison around its circumference. A uniform testing specimen was produced from each area using a microtome. Each specimen measured $3 \mathrm{~mm} \times 1 \mathrm{~mm}$ in cross section and was of length $6 \mathrm{~mm}$. Indentation testing was conducted in a controlled environment of $100 \%$ humidity at $37 \pm 1^{\circ} \mathrm{C}$. Results. 52 test samples were obtained from eight labrae. The mean modulus of the glenoid labrum was 69.7 MPa (S.D. \pm 36.2 ). The anterosuperior portion of the labrum had a higher modulus than the posterioinferior portion $(p=0.0075)$.

Conclusions. The greater modulus of the anterosuperior portion of the labrum supports the theory that this area is anatomically different to the rest of the labrum and resists compressive loads.

Clinical Relevance. These results may explain why the common type of SLAP lesions seen demonstrate failure at the interface between the labrum and the glenoid rather than within the substance of the labrum itself.

Key Words. in-vitro; material properties, compressive testing 


\section{Introduction}

SLAP lesions of the superior aspect of the glenoid labrum are classified as I-X(1-4). These can be divided into two broad categories, those that are an intra-substance tear and those that fail at the interface between the labrum and underlying glenoid or detachment. Type II consists of a detachment of the labrum from the underlying glenoid; type $\mathrm{VI}$ is a combination of a detachment and a mid-substance tear. The majority of SLAP lesions found at arthroscopy are type II (2;4-7) and where the injury mechanism is known it is found to be compression and pure traction suggesting impingement between the humeral head and the glenoid or torsional tension along the biceps anchor (8), (9). It is thought that a tight posterior capsule and the development of a GRID (Glenohumeral Internal Rotation Deficit) is the critical first stage in the development of SLAP lesions in throwing athletes (10). Biomechanical studies have confirmed that pure traction and external rotation with abduction will recreate a SLAP lesion (11)'(12;13). No studies have tested the compression mechanism. In addition, although the tensile properties of the labrum are known to vary around the labrum(14), there has been only one study that measured the compressive properties of the labrum (15). The interpretation of this study is limited in that the tissue was embalmed and formalin fixation is known to change the mechanical properties of tissues (16).

Therefore, the aim of this study was to examine the biomechanical behaviour of the human glenoid labrum under compression in fresh frozen cadaveric shoulders and to test the specific hypothesis that there is a difference in the compressive stiffness between the superior and inferior part of the labrum. This would explain why SLAP lesions would appear in some regions of the labrum more than others when compressed in impingement injury mechanisms.

\section{Materials and Methods}

This study was approved by a local ethics committee and sixteen fresh frozen cadaveric shoulders were obtained from a tissue bank. All the shoulders had been harvested with the scapula and proximal half of the humerus intact. The specimens were stored at $-20^{\circ} \mathrm{C}$ when not in use and sprayed with physiological saline during dissection and testing. All specimens were thawed in room temperature overnight prior to use.

Each specimen was initially dissected preserving the rotator cuff musculature. The cuff was excised from its insertion on the humerus, in order to allow safe disarticulation of the joint without intra-articular iatrogenic damage. The articular surfaces were graded according to the Outerbridge classification (17), and the gross anatomy and dimensions of the labrae were recorded with Vernier callipers. Any specimens that demonstrated degeneration tears or fibrillation of the labrum, or degenerative changes greater than grade I of either articular surface were withdrawn from the study. After initial inspection, 8 specimens had significant degenerative changes and were withdrawn from the study.

The remaining eight labra had a mean age of 61 (range 47-70) from 4 right and 4 left shoulders. Each labrum was harvested carefully from the underlying glenoid surface and divided into eight segments around its circumference (Figure 1). Each section was straightened out and cryo-clamped onto a microtome for accurate freeze- 
fracturing of the sections into $1 \mathrm{~mm}$ thick slices in a plane parallel to the collagen fibres. The freeze-fracture was accomplished with high velocity. Rapid freeze/thawing under defined conditions is known to have no effect on loadelongation curves of spine longitudinal-ligament test-samples (18). There is no similar information on cartilage, labrum or meniscus.

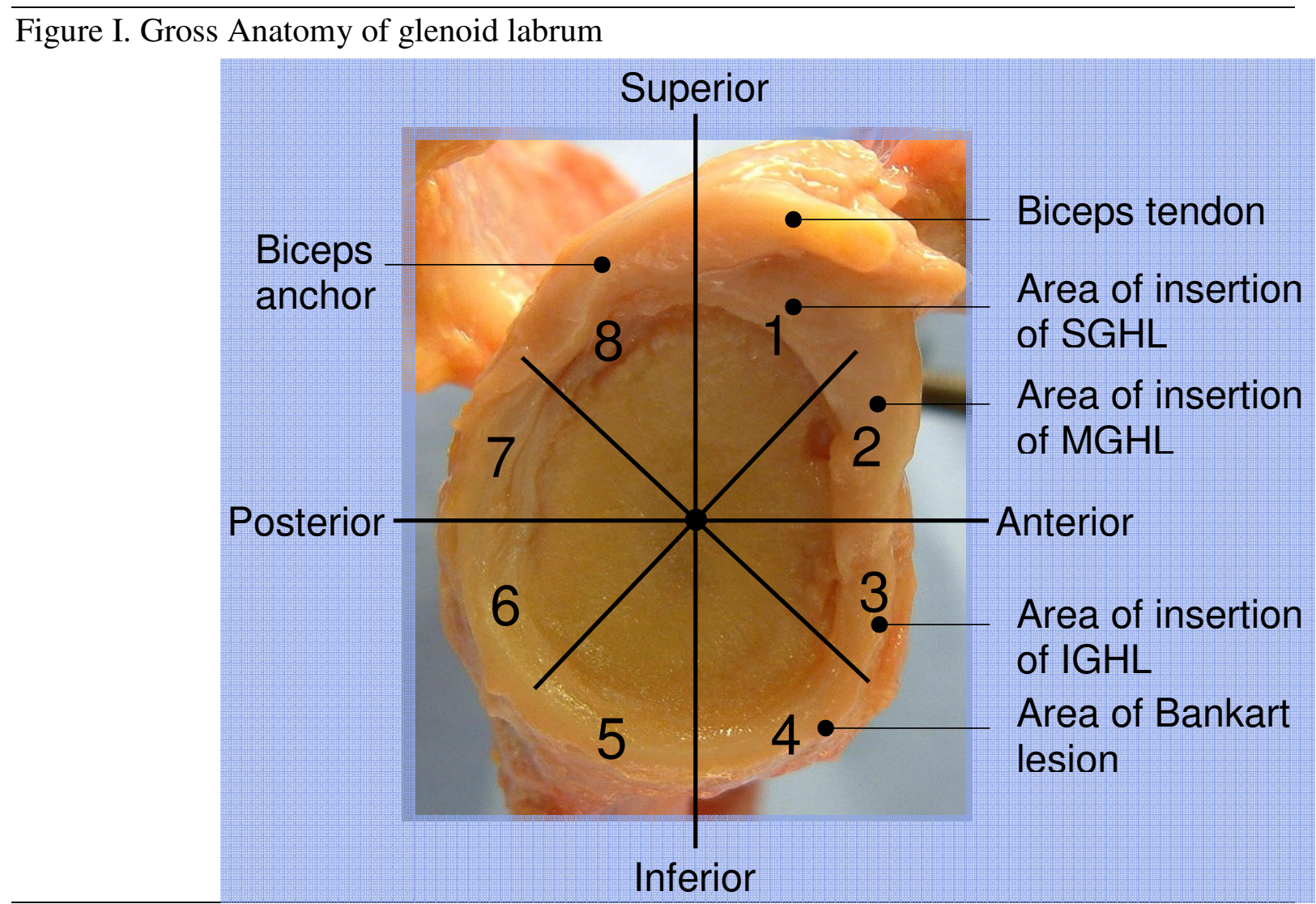

Each slice was remounted to the microtome by its free edge and cut again. This produced a testing sample with a width of $3 \mathrm{~mm}$, a thickness of $1 \mathrm{~mm}$ and a length between $6 \mathrm{~mm}$ and $8 \mathrm{~mm}$ (Figure 2). All the test samples were measured directly after cutting whilst still frozen using electronic callipers (Mitutoyo, Andover, Hampshire, U.K.) and any that deviated from the desired dimensions by more than $0.1 \mathrm{~mm}$ were rejected for further testing.

All testing was carried out on an Instron materials testing machine (Instron 5565, High Wycombe, Bucks, UK), with accompanying Merlin software (v.4). A $10 \mathrm{~N}$ loadcell (accurate to within $\pm 0.25 \%$ of load applied) was used; this was calibrated before each testing session. An environmental chamber that could regulate the temperature to $37 \pm 1{ }^{\circ} \mathrm{C}$ and maintain $100 \%$ relative humidity was used during testing (18).

Each test sample was inserted into a stainless steel trough with a depth of $1 \mathrm{~mm}$ and width of $3 \mathrm{~mm}$, allowing an exact fit of the test sample (Figure 3). Both ends of the test samples were not enclosed allowing some free movement of fluid in and out of the sample during testing. The indenter used was a $3 \mathrm{~mm}$ diameter stainless steel sphere. 
Figure II. Diagram of a single glenoid portion with test sample orientation within core region.

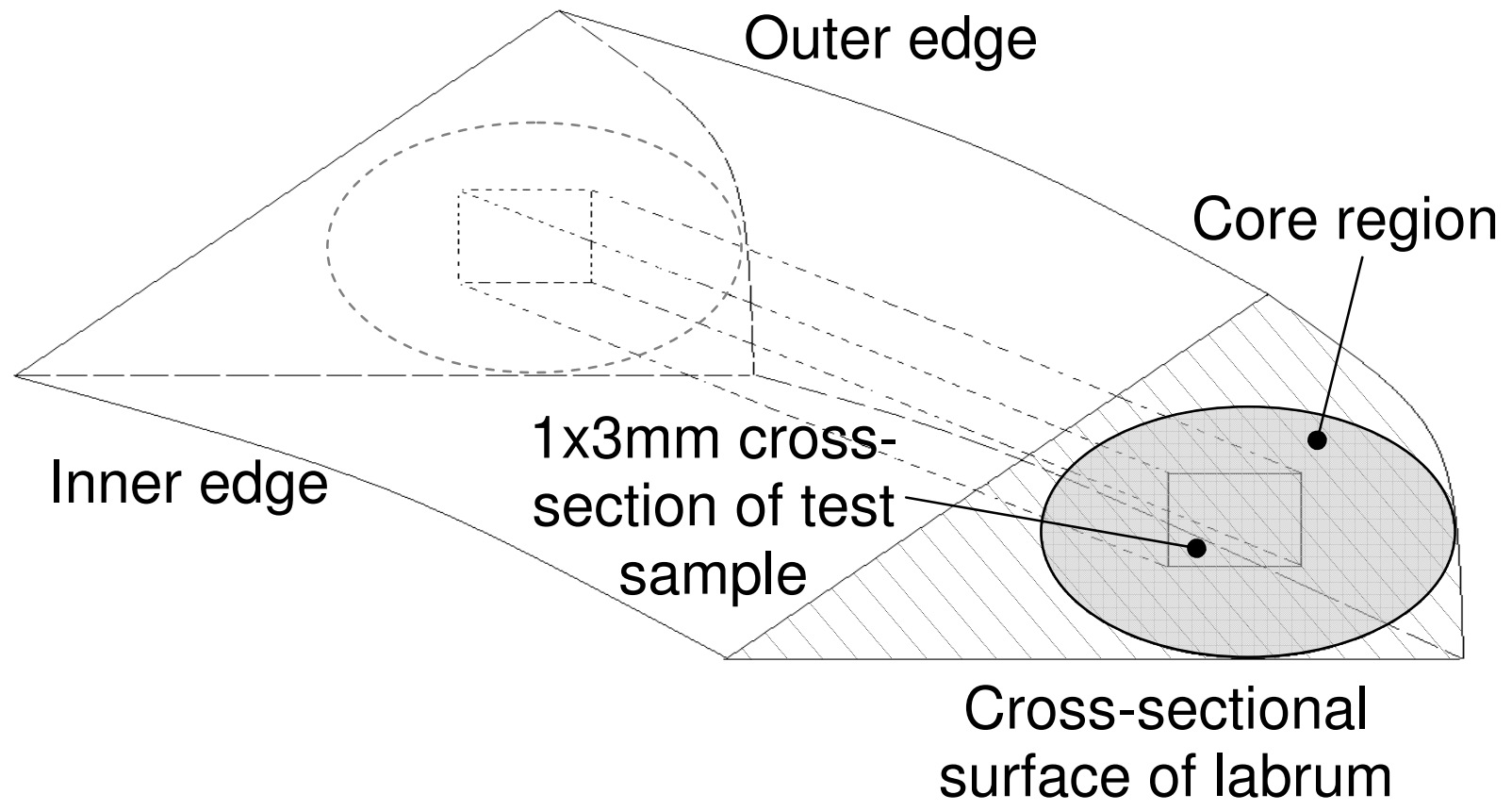

Figure III: Image of the well used for testing. The sample's dimensions allow for an exact fit to the well's slot. The indentor is impermeable and $3 \mathrm{~mm}$ in diameter.

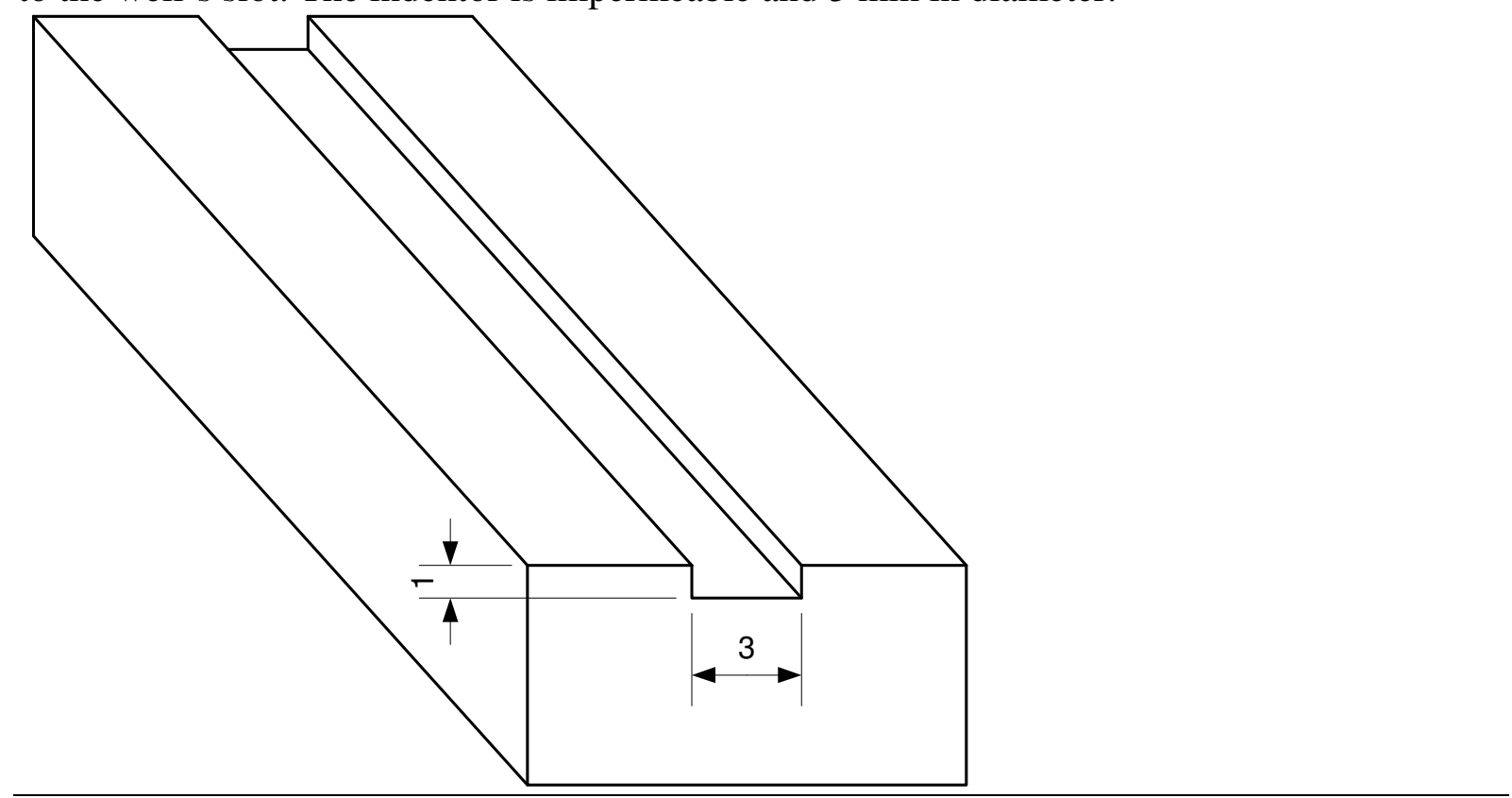

The test-sample was allowed to adjust to the environmental conditions for 5 minutes prior to testing. The specimen was tested in compression so that the indenter was placed perpendicular to the long axis of the fibres as follows:

1. Precycling with force and displacement control at a $10 \mathrm{~mm} / \mathrm{min}$ displacement rate. The specimen was cycled between $0 \mathrm{~mm}$ and $0.5 \mathrm{~N}$ load until the hystereses curves were overlapping.

(Zero displacement was defined by manually lowering the indenter onto the test sample until a load was recorded. Overlapping curves were defined as a 
difference of less than $0.01 \mathrm{~mm}$ measured at the ascending $0.25 \mathrm{~N}$ load position between two consecutive cycles.)

2. Rezeroing the displacement. A load of $0.01 \mathrm{~N}$ was now placed on the preconditioned test-sample, so that a new zero position could be documented accurately.

(This 'tare load' was used, because of the very low stiffness response of biological tissues with low loads (commonly called the 'toe-region'); the tare load allows a robust repeatible zero displacement to be established.)

3. Final precycling. The main testing commenced with a further 10 precycles to $0.5 \mathrm{~N}$.

(This ensured complete preconditioning after the readjustment of the sample.)

4. Tensile loading. The test-sample was loaded up to $1.5 \mathrm{~N}$.

5. Stress relaxation. The test-sample was allowed to stress-relax for 5 minutes by keeping the displacement constant throughout this time. (In pilot testing, a 5-minute period of stress relaxation was enough for all samples tested to reach an equilibrium state.)

6. Tensile loading. The test-sample was returned to zero displacement and was loaded to $3 \mathrm{~N}$.

7. Stress relaxation. A second 5-minute period of stress relaxation was allowed.

8. Tensile loading. The test-sample was returned to zero displacement and was loaded to $5 \mathrm{~N}$.

A typical load versus displacement graph is presented in Figure 4.

Figure IV: Typical graph of compressive load against normalised (to the thickness) compressive displacement (loading - stress relaxation - unloading - loading - stress relaxation - unloading - loading).

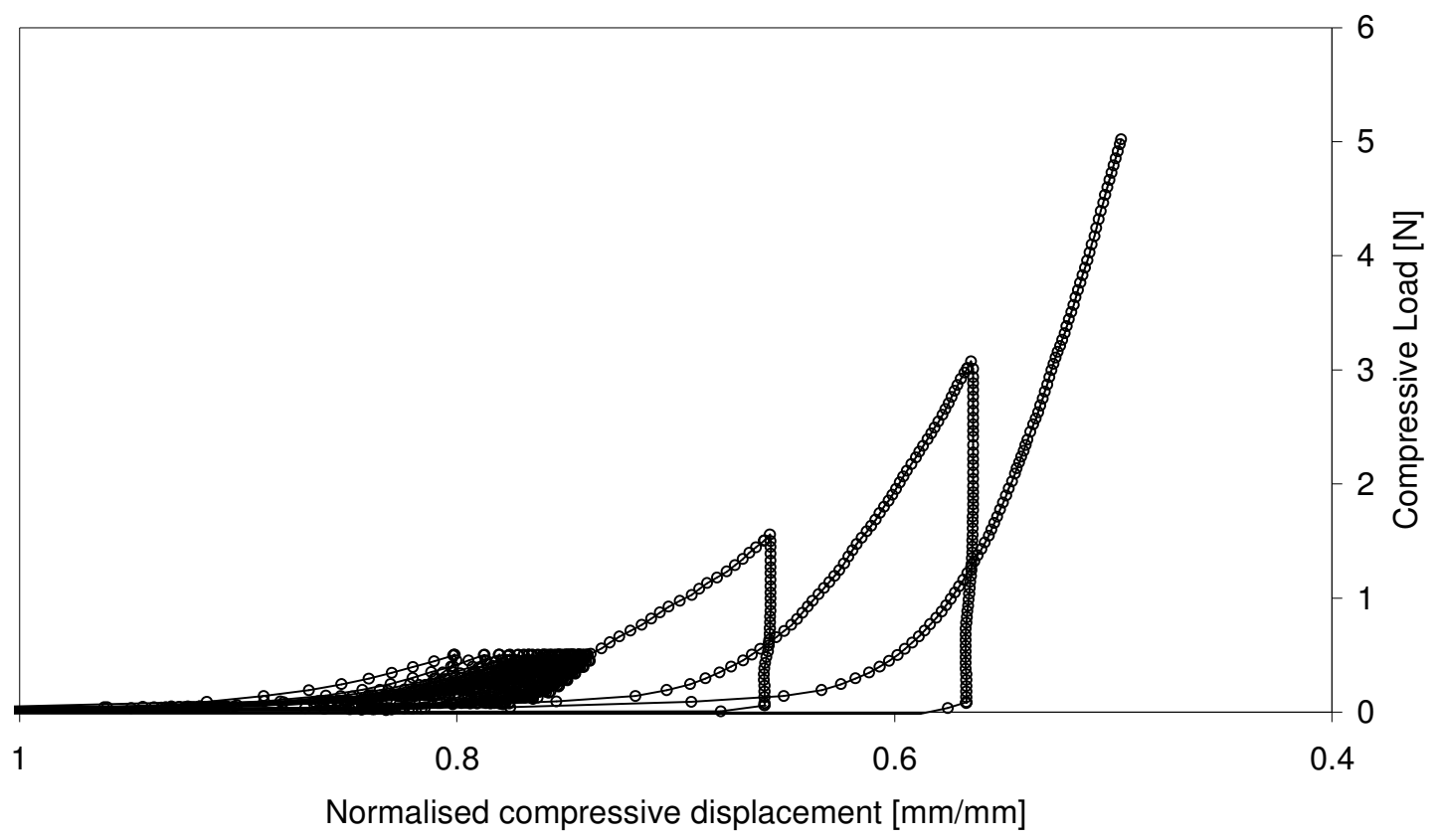


A compressive modulus for each test-sample was determined from the linear portion of the stress-strain curve at final loading; that is after the second period of stress relaxation. A tangent compressive modulus was similarly calculated prior to the first and second periods of stress relaxation. The strain was re-calculated after the second stress relaxation due to the change in thickness of the sample. The modulus was obtained using linear regression analysis.

The hypothesis was tested by comparing the compressive modulus at final loading for each possible combination of 4 adjacent portions against the other 4 portions for a significant difference using a one-tailed paired Students t-test with an alpha level of 0.05. This resulted in 4 comparisons that were made, with a Bonferroni correction applied. Statistical significance was therefore demonstrated if $p<0.0125$. Statistically significant results are presented.

\section{Results}

Due to the varying dimensions amongst labrae, a reliable test-sample that had a consistent 3 by $1 \mathrm{~mm}$ cross-section along its whole length could not be obtained for all eight positions on each labrum. This resulted in 52 out of 64 potential test-samples from eight labrae.

The mean compressive modulus (post stress relaxation) of the glenoid labrum was 69.7 MPa (S.D. 36.2). The average post stress relaxation tangent compressive modulus for each portion of the glenoid labrum is presented in Table 1. The tangent compressive modulus after the first period of stress relaxation increased by a mean of 22.9 MPa (S.D. 6.2) $(p<0.001)$ compared to prior stress relaxation and increased by a further $32.9 \mathrm{MPa}(\mathrm{S} . \mathrm{D} .32 .9)(\mathrm{p}<0.001)$ after the second period of stress relaxation.

For the final compressive modulus, portions 1-3 and 8 were significantly stiffer than portions 4-7 $(p=0.0075)$. The posterioinferior quadrant had a significantly lower modulus than the anterioinferior quadrant $(p<0.01)$.

Table 1: Average post stress relaxation modulus (SD) for each portion of the glenoid labrum.

\begin{tabular}{cccccccccc}
\hline $\begin{array}{c}\text { Portion } \\
\mathrm{n}=52\end{array}$ & 1 & 2 & 3 & 4 & 5 & 6 & 7 & 8 \\
\hline Tangent & & & & & & & & \\
compressive & 79.2 & 85.7 & 83.1 & 72.3 & 54.4 & 51.3 & 56.9 & 79.7 \\
Modulus & $(19.4)$ & $(78.5)$ & $(46.0)$ & $(26.5)$ & $(15.4)$ & $(31.9)$ & $(27.8)$ & $(26.1)$ \\
MPa & & & & & & & & \\
\hline
\end{tabular}




\section{Discussion}

The principal finding of this study was that inferoposterior part of the labrum has a lower compressive stiffness than the anterosuperior quadrant.

As expected with biological tissue the standard deviations are large, especially for portion 2, which is known to have the most anatomical variation $(5 ; 19 ; 20)$. This is believed to be the only data available for fresh, hydrated labral tissue; prior work (15) has been in formalin-fixed tissue, that is known to be stiffer than when unfixed (16). Although not comparable, this prior work did demonstrate that the compressive modulus for the superior half of the labrum was significantly higher than that of the inferior labrum.

In order to examine the dynamic viscoelastic behaviour of the labrum under cyclically compressive loading, and as such, mimic the pattern of loading experienced through activities of daily living, the specimens were cycled followed by a period of stress relaxation and moduli compared both prior to and after equilibrium under a constant load. Activities of daily living (21) are a mixture of constant load and constant displacement, interspersed with varying loading rates. During these activities, soft connective tissues of joints are reported to work in the toe-region of their stress-strain curve (22-24). The tangent modulus at the end of the first period of stress relaxation was significantly less than that at the end of the second stress relaxation, which in turn was significantly less than the final elastic modulus. As such, the labral tissue stiffened through each period of stress relaxation, most probably due to net fluid extrusion.

Previously, the superior region of the labrum (positions 1 and 2) has been demonstrated to have significantly lower tensile elastic modulus and yield stress when compared to the inferior region (position 4 and 5) (14) (Figure 5). This suggests that the anterosuperior part of the labrum is good in compression and weak in tension and anatomically different to the remainder of the labrum.

Figure V: Mean values for (a) the tensile modulus and (b) indentation stiffness at each portion of the labrum after stress relaxation, averaged among specimens. All values are in MPa. The tensile modulus values are taken from Smith et al (2008) ${ }^{31}$.

(a)

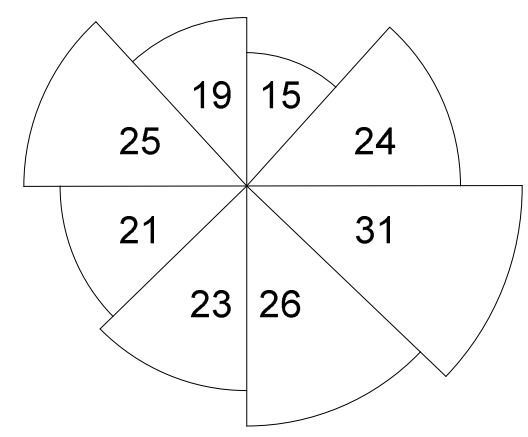

(b)

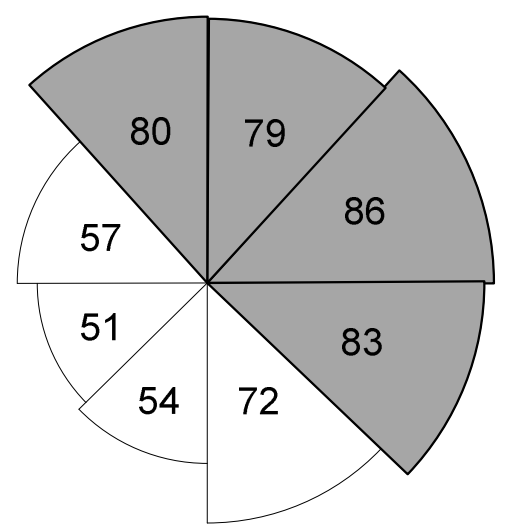

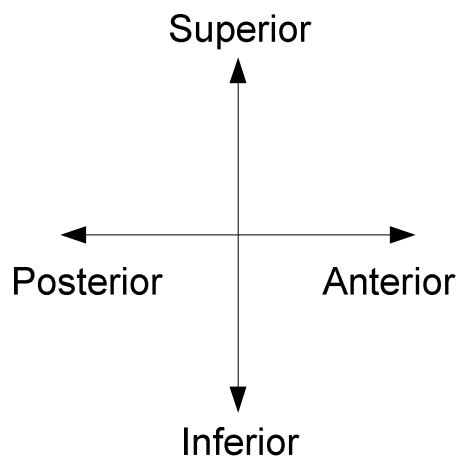


It could be concluded that this increased resistance to compression is why the majority of SLAP lesions involve failure between the labrum and the glenoid (i.e. detachment), rather than a mid-substance failure. The superior labrum being able to resist the proximal subluxation of the humeral head pinching it against the glenoid until failure occurs at this interface. Although to confirm this, further work needs to be aimed at recreating push off lesions of the superior labrum to see if the familiar patterns of SLAP lesions are recreated.

The previous work suggesting a reduced tensile elastic modulus (equivalent in definition to the compressive modulus defined in this paper) in this region may be thought to explain the intra-substance tears as pull off lesions (14). However, the position of failure is between parallel fibres in a type III or IV lesion, whereas the direction of tensile testing in the published literature was along the direction of the fibres. No work has been produced on the radial tensile properties of the labrum.

The anterosuperior region is the most variable part of the labrum which appears to be detached in utero $(25 ; 26)$. This difference in utero may be the cause of the numerous variations seen in that part of the labrum in the adult including a complete absence, a sub-labral foramen, a sub-labral recess and the Buford complex (20;27-31). These anatomical variations may make certain patients more susceptible to tears in this region; the Buford complex has been associated with a higher rate of SLAP lesions $(32 ; 33)$.

It could be hypothesised that intra-substance lesions and detachment lesions have different mechanisms of injury and is unlikely that a type II lesion progresses to a type III lesion if unaddressed, as the point of failure is different.

These results aid the clinician in determining what forces will cause pathological injuries and the likely pattern of injuries produced. They also demonstrate the forces which any repair is likely to be subjected to after surgery.

This study was not without its problems and we believe that there are a number of ways in which it could be improved. For example, we found that the number of precycles prior to reaching equilibrium was not consistent; this may have been due to the previous long-term preservation of the tissues (34). Therefore, in future we would propose the immediate use of unfrozen specimens. There are a number of ways of reducing the large standard deviations found, these include having specimens from a small, relevant age range(35) or significantly increasing the number of specimens. These suggested improvements and hence acknowledged limitations do not negate the results of this study.

\section{Conclusions}

This study has demonstrated that the human glenoid labrum's compressive behaviour varies around its circumference. The greater modulus of the anterosuperior portion of the labrum supports the theory that this area is anatomically different to the rest of the labrum and resists compressive loads. 


\section{Reference List}

(1) Morgan CD, Burkhart SS, Palmeri M, Gillespie M. Type II SLAP lesions: three subtypes and their relationships to superior instability and rotator cuff tears.

Arthroscopy 1998; 14(6):553-565.

(2) Maffet MW, Gartsman GM, Moseley B. Superior labrum-biceps tendon complex lesions of the shoulder. Am J Sports Med 1995; 23(1):93-98.

(3) Powell SE, Nord KD, Ryu RKN. The diagnosis, classification and treatment of SLAP lesions. Oper Tech Sports Med 2004; 12(2):99-110.

(4) Snyder SJ, Karzel RP, Del PW, Ferkel RD, Friedman MJ. SLAP lesions of the shoulder. Arthroscopy 1990; 6(4):274-279.

(5) Snyder SJ, Banas MP, Karzel RP. An analysis of 140 injuries to the superior glenoid labrum. J Shoulder Elbow Surg 1995; 4(4):243-248.

(6) Park JH, Lee YS, Wang JH, Noh HK, Kim JG. Outcome of the isolated SLAP lesions and analysis of the results according to the injury mechanisms. Knee Surg Sports Traumatol Arthrosc 2008; 16(5):511-515.

(7) Kampa RJ, Clasper J. Incidence of SLAP lesions in a military population. J $R$ Army Med Corps 2005; 151(3):171-175.

(8) Jobe CM. Posterior superior glenoid impingement: expanded spectrum. Arthroscopy 1995; 11(5):530-536.

(9) Burkhart SS, Morgan CD. The peel-back mechanism: its role in producing and extending posterior type II SLAP lesions and its effect on SLAP repair rehabilitation. Arthroscopy 1998; 14(6):637-640.

(10) Burkhart SS, Morgan CD, Kibler WB. The disabled throwing shoulder: spectrum of pathology. Part II: evaluation and treatment of SLAP lesions in throwers. Arthroscopy 2003; 19(5):531-539.

(11) Bey MJ, Elders GJ, Huston LJ, Kuhn JE, Blasier RB, Soslowsky LJ. The mechanism of creation of superior labrum, anterior, and posterior lesions in a dynamic biomechanical model of the shoulder: the role of inferior subluxation. $J$ Shoulder Elbow Surg 1998; 7(4):397-401.

(12) Kuhn JE, Lindholm SR, Huston LJ, Soslowsky LJ, Blasier RB. Failure of the biceps superior labral complex: a cadaveric biomechanical investigation comparing the late cocking and early deceleration positions of throwing. Arthroscopy 2003; 19(4):373-379.

(13) Mihata T, McGarry MH, Tibone JE, Fitzpatrick MJ, Kinoshita M, Lee TQ. Biomechanical Assessment of Type II Superior Labral Anterior-Posterior (SLAP) Lesions Associated With Anterior Shoulder Capsular Laxity as Seen in Throwers: A Cadaveric Study. Am J Sports Med 2008;doi:10.1177/0363546508315198 (available at ajs.sagepub.com). 
(14) Smith CD, Masouros SD, Hill AM, Wallace AL, Amis AA, Bull AMJ. Tensile properties of the human glenoid labrum. Journal of Anatomy 2008; 212(1):49-54.

(15) Carey J, Small CF, Pichora DR. In situ compressive properties of the glenoid labrum. J Biomed Mater Res 2000; 51(4):711-716.

(16) Wilke HJ, Krischak S, Claes LE. Formalin fixation strongly influences biomechanical properties of the spine. J Biomech 1996; 29(12):1629-1631.

(17) Outerbridge RE. The eitiology of chondromalacia patellae. The Journal of Bone and Joint Surgery (British) 1961; 43:752-757.

(18) Tkaczuk H. Human cartilage stiffness. In vivo studies. Clin Orthop Relat Res 1986; 206:301-312.

(19) Pfahler M, Haraida S, Schulz C, Anetzberger H, Refior HJ, Bauer GS et al. Age-related changes of the glenoid labrum in normal shoulders. J Shoulder Elbow Surg 2003; 12(1):40-52.

(20) Prodromos CC, Ferry JA, Schiller AL, Zarins B. Histological studies of the glenoid labrum from fetal life to old age. J Bone Joint Surg Am 1990; 72(9):13441348.

(21) Murray IA, Johnson GR. A study of the external forces and moments at the shoulder and elbow while performing every day tasks. Clin Biomech (Bristol, Avon ) 2004; 19(6):586-594.

(22) Beynnon BD, Fleming BC. Anterior cruciate ligament strain in-vivo: a review of previous work. J Biomech 1998; 31(6):519-525.

(23) Noyes FR, Butler DL, Grood ES, Zernicke RF, Hefzy MS. Biomechanical analysis of human ligament grafts used in knee-ligament repairs and reconstructions. J Bone Joint Surg Am 1984; 66(3):344-352.

(24) Cerulli G, Benoit DL, Lamontagne M, Caraffa A, Liti A. In vivo anterior cruciate ligament strain behaviour during a rapid deceleration movement: case report. Knee Surg Sports Traumatol Arthrosc 2003; 11(5):307-311.

(25) Fealy S, Rodeo SA, Dicarlo EF, O'Brien SJ. The developmental anatomy of the neonatal glenohumeral joint. J Shoulder Elbow Surg 2000; 9(3):217-222.

(26) Gardner E, Gray DJ. Prenatal development of the human shoulder and acromioclavicular joints. Am J Anat 1953; 92(2):219-276.

(27) Buford D, Snyder SJ, Veneziani S, Wuh HCK. The Buford complex -The loose anterior superior labrum/middle glenohumeral ligament complex: an anatomic variant. Arthroscopy 1992; 8(3):402.

(28) Clavert P, Kempf JF, Wolfram-Gabel R, Kahn JL. Are there age induced morphologic variations of the superior glenoid labrum? About 100 shoulder arthroscopies. Surgical and Radiologic Anatomy 2005; 27(5):385-388. 
(29) Harzmann HC, Burkart A, Wortler K, Vaitl T, Imhoff AB. Normal anatomical variants of the superior labrum biceps tendon anchor complex. Anatomical and magnetic resonance findings. Orthopade 2003; 32(7):586-594.

(30) Rao AG, Kim TK, Chronopoulos E, McFarland EG. Anatomical variants in the anterosuperior aspect of the glenoid labrum: a statistical analysis of seventy-three cases. J Bone Joint Surg Am 2003; 85-A(4):653-659.

(31) Waldt S, Metz S, Burkart A, Mueller D, Bruegel M, Rummeny EJ et al. Variants of the superior labrum and labro-bicipital complex: a comparative study of shoulder specimens using MR arthrography, multi-slice CT arthrography and anatomical dissection. Eur Radiol 2006; 16(2):451-458.

(32) Bents RT, Skeete KD. The correlation of the Buford complex and SLAP lesions. J Shoulder Elbow Surg 2005; 14(6):565-569.

(33) Nam EK, Snyder SJ. The diagnosis and treatment of superior labrum, anterior and posterior (SLAP) lesions. Am J Sports Med 2003; 31(5):798-810.

(34) Moon DK, Woo SL, Takakura Y, Gabriel MT, Abramowitch SD. The effects of refreezing on the viscoelastic and tensile properties of ligaments. J Biomech 2006; 39(6):1153-1157.

(35) Woo SL, Hollis JM, Adams DJ, Lyon RM, Takai S. Tensile properties of the human femur-anterior cruciate ligament-tibia complex. The effects of specimen age and orientation. Am J Sports Med 1991; 19(3):217-225. 